\title{
Influencing Factors of Undermet Care Needs of the Chinese Disabled Oldest Old People When Their Children Are Both Caregivers and Older People: A Cross-Sectional Study
}

\author{
Qilin Zhang ${ }^{1,+} \mathbb{D}$, Yanli $\mathrm{Wu}^{1,+}$ and Erpeng Liu ${ }^{2, *} \mathbb{C}$ \\ 1 Center for Social Security Studies, Wuhan University, Wuhan 430072, China; qilinzhang@whu.edu.cn (Q.Z.); \\ yanliwu@whu.edu.cn (Y.W.) \\ 2 Institute of Income Distribution and Public Finance, Zhongnan University of Economics and Law, \\ Wuhan 430073, China \\ * Correspondence: whubest@163.com \\ + Co-first authors, these authors contributed equally to this work and should be regarded as equal.
}

Received: 1 August 2020; Accepted: 18 September 2020; Published: 25 September 2020

\begin{abstract}
We examined the influencing factors of the undermet care needs of the Chinese disabled oldest old people when their children are both caregivers and are themselves older people. Data were obtained from a cross-sectional survey: the Chinese Longitudinal Healthy Longevity Survey (CLHLS) in 2018. The study participants included 1617 disabled oldest old people whose primary caregiver were their children or children-in-law and were aged 60 years and over. The results showed that the prevalence of undermet needs remained high, with $49.6 \%$ disabled oldest old people reporting undermet care needs. Binary logistic regression analysis revealed that living in a rural area $(\mathrm{OR}=1.309,95 \% \mathrm{CI}=1.133-1.513)$ and a higher frailty index $(\mathrm{OR}=1.103,95 \% \mathrm{CI}=1.075-1.131)$ were significantly positively associated with higher odds for undermet care needs, while a higher annual household income ( $\mathrm{OR}=0.856,95 \% \mathrm{CI}=0.795-0.923)$, more financial support from children $(\mathrm{OR}=0.969,95 \% \mathrm{CI}=0.941-0.997)$, higher care expenditures $(\mathrm{OR}=1.044,95 \% \mathrm{CI}=1.002-1.088)$, better caregiver's performance (OR $=0.282,95 \% \mathrm{CI}=0.196-0.407)$ and sufficient income to pay for daily expenses ( $\mathrm{OR}=0.710,95 \% \mathrm{CI}=0.519-0.973)$ were significantly inversely associated with higher odds for undermet care needs. This evidence suggests the importance of policies to establish a community-based socialized long-term care system and supporting family caregivers of the disabled oldest old people.
\end{abstract}

Keywords: undermet care needs; Chinese disabled oldest old people; older children; influencing factors

\section{Introduction}

Population aging is rapidly accelerating worldwide, especially in China. By 2019, the number of Chinese older people over the age of 60 years had reached 254 million, accounting for $18.1 \%$ of the total population [1]. It is estimated that by 2050, the number of older people over the age of 60 years will increase to a peak of 488 million in China, representing $35.6 \%$ of the total population [2]. At the same time, due to the increase in life expectancy, the trend of aging is also more obvious in the oldest old people. In the past 10 years, the population of Chinese older people aged 80 years and older has been growing at an average annual rate of $4.7 \%$, which is significantly faster than the growth rate of older people aged 60 years and older [3]. In 2013, the number of Chinese older people over the age 
of 80 years had reached 22.6 million. It is estimated that by 2050, this number will increase 4-fold, reaching 90.4 million—becoming the world's largest group of oldest old people [4].

China is an unhealthy aging society, and its disabled older population is developing rapidly [5-7]. According to the Fourth Sampling Survey on the Living Conditions of Urban and Rural Older People in China, the number of partially disabled and completely disabled older people has reached 40.63 million [8]. It is estimated that by 2030 and 2050, the number of older people with disabilities in China will further increase to 61.68 million and 97.5 million, respectively [9]. At the same time, the oldest old people are mostly unhealthy. Due to the deterioration of their physical functions and chronic disease, the probability of suffering from disability and dementia among the oldest old people is significantly higher than those of younger older people aged 60 to 79 years [10-12]. Moreover, the proportion of older adults who cannot take care of themselves gradually increases with age, especially in the period of 80 to 90 years old, when the proportion of older adults who cannot take care of themselves increases the fastest $[13,14]$. Therefore, the demand for care is the strongest among the disabled oldest old people in China.

The care of the oldest old people in China is still provided by families, which is a traditional and strong inertial old-age care model [15-18]. At the same time, the probability of widowhood is high among the oldest old population [19-21]; therefore, their children or children-in-law become their main body of family care [22-25]. The reasons for this phenomenon are as follows: First, the economic status of the oldest old people is poor [26], and they cannot afford the care services provided by the market. Influenced by the long-term low wage policy, the oldest old people have few savings. Additionally, due to China's undeveloped pension system, most older people have very low pensions, with an average level of 100 to 200 RMB (Ren Min Bi, Chinese Yuan, about 14.64 to 29.28 dollars in September 2020) per month $[27,28]$. The proportion of older adults aged 80 years and older receiving the old age allowance is $13.64 \%$ [29], and the old age allowance in most regions is only 100 RMB (about 14.64 dollars in September 2020) per month [30]. Second, the level of public care services provided by the government is low, and the capacities of the market and social organizations to provide care services are at the initial stages [31,32]. Thus, it is difficult for older people to obtain formal care service support. Finally, the current generation of the oldest old people were born before the 1940s and were greatly influenced by the traditional culture of filial piety [33-35]. It is believed that caring for older parents is an obligation and has traditionally been highly valued by children [36,37]. People take "living in a nursing home" as a manifestation of a lack of filial piety, which is not conducive to family solidarity. Therefore, family care, especially by children, has become the main type of care for the oldest old people in China. At the same time, in the context of rapid aging, most children of the Chinese oldest old have entered the stage of aging. Providing care for the oldest old parents by their older children is becoming one of the care models and will be increasingly common in China [24,38].

The outbreak of the COVID-19 had a significant impact on the care of Chinese older people, especially the family care model. The Ministry of Civil Affairs, in charge of older people's care services, had issued some policy support and guidance for institutional older people care, such as "Guidelines for Prevention and Control of COVID-19 Epidemic High-risk Areas and Infected Older People Care Institutions". However, no corresponding policy support measures have been introduced for older people in family care. The impacts are not limited to older people cared by family members. Those older people suffering from chronic diseases could not get medicines in time. Moreover, older people were in a state of panic, restricted at home due to their inability to use information equipment proficiently.

In the context of accelerating aging in China, our study is the first to explore the care model of older children taking care of their oldest old parents. In this care model, whether the care provided meets the needs of the disabled oldest old people and its influencing factors should be highly valued. In previous studies, many disabled older people living with family members reported that the assistance they received did not fully meet their needs [24,39], and these people were viewed as having undermet care needs, i.e., they needed more care due to the insufficient amount of assistance they received [40]. Similar to the unmet needs of receiving no help, undermet care needs of receiving 
inadequate personal assistance in ADL (activities of daily living) are serious threats to the health status and life quality of older people with disabilities [40], including more limited ADL, emergency-room visits and hospitalizations [41-43], increased psychological stress [44], and higher rate of mortality [45]. Therefore, identifying the factors associated with the undermet care needs of the disabled oldest old people and taking appropriate interventions are particularly important.

While previous studies have explored the influencing factors for undermet care needs of older people, some limitations exist. First, most studies are conducted in developed countries, with only a few studies conducted in China, and the data in these studies were too old to reflect the present situation of China $[39,46]$, especially in the context of the accelerating aging and increasing number of older people. Second, the sample of the disabled oldest old people (age 80+), who tend to need the most care, was limited and therefore under-represented in previous studies. Third, previous studies on undermet care needs of Chinese older people mostly used Andersen's behavioral model of health services use [47-49], which may not fully consider the cultural characteristics and traditional customs of care in Chinese older people. Last, but most important, the care sources provided were mostly from younger family members in previous studies. Old people, especially the older children as caregivers, had not be considered. Therefore, in this study, we aimed to use the latest nationwide data to explore the influencing factors for the undermet care needs of the Chinese disabled oldest old people when their children are both caregivers and older people themselves.

\section{Materials and Methods}

\subsection{Date Source and Study Population}

This study used data from the Chinese Longitudinal Healthy Longevity Survey (CLHLS), a nationally representative survey jointly performed by the Center for Healthy Aging and Development Studies at Peking University and Duke University. The CLHLS aims to understand the health status and associated social, behavioral, and biological factors among Chinese older people. As currently the largest survey in the world in terms of health and longevity, a baseline survey was conducted in 1998, followed by seven waves of surveys in 2000, 2002, 2005, 2008, 2011, 2014 and 2018 from 22 sample areas in 31 provincial administrative units, which constituted $85 \%$ of the total population and covered East, Central West and Northeast China. The survey randomly selected approximately one-half of the counties in the 22 provinces as primary survey units. Additional details, such as the sampling design, sampling weight and assessment of data quality, could be found in previous studies $[6,7,10,25,50]$.

We used the latest cross-sectional data of CLHLS in 2018, which consist of 15,874 Chinese older people. After filtering for missing values, outliers, etc., our analysis included 1617 disabled oldest old people aged 80 years and over whose primary caregivers were children (sons, daughters) or children-in-law (son-in-law, daughter-in-law) aged 60 years and over. The characteristics of the participants are presented in Table 1. The participants included 387 men and 1230 women. The mean age of the participants was 98.71 years ( $\mathrm{SD}=5.18$ years), with 97.54 years ( $\mathrm{SD}=5.14$ years) for men and 99.07 years $(\mathrm{SD}=5.14$ years) for women. Only $75(4.67 \%)$ participants had spouses, while 1531 $(95.33 \%)$ of participants did not. The average education years of the participants were approximately 1.41 years, indicating that they had low levels of education. There were $374(23.13 \%)$ participants living in a city, $529(32.71 \%)$ participants living in a town and $714(44.16 \%)$ living in rural areas. The mean frailty index of the oldest old people was 0.40 . 
Table 1. Descriptive statistics of the study sample.

\begin{tabular}{|c|c|c|c|}
\hline & Variables & Measurement & n (\%)/mean (SD) \\
\hline \multirow{12}{*}{$\begin{array}{l}\text { Sociodemographic } \\
\text { characteristics }\end{array}$} & & Female $=0$ & $1230(76.07 \%)$ \\
\hline & Sex & Male $=1$ & $387(23.93)$ \\
\hline & Age & Continuous measurements & $98.71(5.18)$ \\
\hline & & No formal education $=1$ & $1116(69.02 \%)$ \\
\hline & Education (years) & 1 to $6=2$ & $415(25.66 \%)$ \\
\hline & & 7 or more $=3$ & $86(5.32 \%)$ \\
\hline & & Without spouse $=0$ & $1531(95.33 \%)$ \\
\hline & Marital status & Have spouse $=1$ & $75(4.67 \%)$ \\
\hline & & City $=1$ & $374(23.13 \%)$ \\
\hline & Place of residence & Town $=2$ & $529(32.71 \%)$ \\
\hline & & Rural $=3$ & $714(44.16 \%)$ \\
\hline & Frailty index & Continuous measurements & $0.40(0.11)$ \\
\hline \multirow{2}{*}{ Family endowment } & Number of cohabitating family members & Continuous measurements & $2.58(1.67)$ \\
\hline & annual household income & Natural logarithm after continuous measurements & $9.98(1.62)$ \\
\hline \multirow{7}{*}{$\begin{array}{l}\text { Intergenerational } \\
\text { relationship }\end{array}$} & Children's financial support & Natural logarithm after continuous measurements & $5.57(3.62)$ \\
\hline & Care expenditure & Natural logarithm after continuous measurements & $3.99(2.62)$ \\
\hline & & Unwilling or Without patience $=0$ & $193(11.94 \%)$ \\
\hline & Caregiver's performance & Willing $=1$ & $1424(88.06 \%)$ \\
\hline & & Never $=1$ & $135(8.35 \%)$ \\
\hline & Share feelings with the caregiver & Sometimes/ Often $=2$ & $132(8.16 \%)$ \\
\hline & & Always $=3$ & $1350(83.49 \%)$ \\
\hline \multirow{6}{*}{$\begin{array}{l}\text { Economic bargaining } \\
\text { power }\end{array}$} & & No $=0$ & $241(14.90 \%)$ \\
\hline & Income sufficient for paying daily expenses & Yes $=1$ & $1376(85.10 \%)$ \\
\hline & & $\mathrm{No}=0$ & $1311(81.08 \%)$ \\
\hline & Have real estate in own name & Yes $=1$ & $306(18.92 \%)$ \\
\hline & Public old age nension & $\mathrm{No}=0$ & $1174(72.60 \%)$ \\
\hline & rubic ora age pension & Yes $=1$ & $443(27.40 \%)$ \\
\hline
\end{tabular}

Ethical approval: The study was approved by the institutional review board at Centre for Social Security Studies of Wuhan University (SSRWU: EP20200701).

\subsection{Measures}

\subsubsection{Disabled Oldest Old People}

Disabled oldest old people are defined as disabled older people aged 80 years and over in this study. Following previous studies [6,7], the ADL disabilities of the oldest old people were measured using the Katz scale [51], which gives a total score (ranging from 6 to 18) of six aspects in daily living disability, including bathing, dressing, bathroom use, indoor transferring, continence and feeding. Depending on the independence of older individuals in completing these activities, they were given a score of 1 (complete independence), 2 (partial independence) or 3 (complete dependence on others), with higher scores indicating a severe daily living disability. The oldest old people who had at least one ADL disability (an ADL score over 6) were classified as disabled oldest old people with long-term care (LTC) needs.

\subsubsection{Older Children}

In the CLHLS, participants were asked: "who is the primary caregiver when you need assistance in the six activities of bathing, dressing, toileting, transferring, continence and feeding?" The answer included 12 categories: spouse, son, daughter-in-law, daughter, son-in-law, son and daughter, grandchildren, other relatives, neighbors, social service, housemaid, and nobody. The older children in our study were the primary caregivers of the disabled oldest old people, including five categories: son, daughter-in-law, daughter, son-in-law, son and daughter, and they all were aged 60 years and older.

\subsubsection{Undermet Care Needs}

Undermet care needs were usually included in unmet care needs. Unmet care needs occur in LTC, when a person with disabilities for which help is needed is unavailable or insufficient [52]. Followed by the previous study, absent and insufficient assistance in personal activities of ADL were named unmet and undermet care needs, respectively $[40,46]$, and we use the term "undermet care needs" to define insufficient assistance in personal activities of ADL among the disabled oldest old people in this study. 
The undermet care needs of the disabled oldest old people were measured based on individual's self-reported response to the question, "Do you think the care you received could meet your needs?" Responses to this question fell into three categories: not met, partially met and fully met. In this study, both the disabled oldest old people who responded partially met and not met were classified as having undermet needs, following the practices of previous research $[39,47]$. This categorization allowed us to dichotomize the responses into two categories: fully met care needs (coded as 0 ) and undermet care needs (coded as 1).

\subsubsection{Influencing Factors of Undermet Care Needs}

According to a review of previous research, the influencing factors of the undermet care needs of the disabled oldest old people were divided into the following categories in this study: (1) sociodemographic characteristics, including sex, age, education, marital status, place of residence and frailty index [46,53-56]. The frailty index was composed of eight parts, including the ADL, IADL (instrumental activities of daily living), objective physical performance, cognitive function, chronic disease, self-rated and interviewer-rated health, visual and hearing impairment, and number of times suffered from a serious illness in the past 2 years, which ranged from 0 to 1 , with higher scores indicating weaker physical and mental functions of the oldest old people [57,58]. It should be pointed out that the Chinese version of MMSE (Mini-mental State Examination) is mainly used to measure the cognitive function of the older people, which is considered to be effective and applicable [6,12]; (2) family endowment, also called family resource, includes the human resources, economic resources, material resources, and social network resources which is the family actually or potentially owns. In our research, the measurement of family endowment mainly includes the number of cohabitating family members [47,59] and annual household income [60,61]. Previous studies have shown that the better the family endowment, the more care resources older people can obtain and the lower their undermet care needs; (3) intergenerational relationship, including children's financial support [62-64], care expenditure $[65,66]$, caregiver's performance $[46,47]$ and the frequency of sharing feelings with the caregiver $[67,68]$ and (4) economic bargaining power, including whether the income was sufficient for paying for daily expenses or not $[47,69]$, having real estate in one's own name or not and receiving the public old age pension or not $[66,70]$. Descriptive statistics of the variables are shown in Table 1.

\subsection{Statistical Analysis}

The data were analyzed using Stata (Stata version 14.0 for Windows, StataCorp LP, College Station, TX, USA). We present descriptive statistics. The results are expressed as the mean (standard deviation) for continuous variables and the number (proportion) for categorial variables. The undermet care needs and sociodemographic characteristics of the disabled oldest old people were analyzed using t-test and Chi-square test. Binary logistic regression analysis was used to investigate the association between undermet care needs and the four categories of influencing factors.

\section{Results}

The sociodemographic characteristics of the disabled oldest old people according to undermet care needs in this study are shown in Table 2. Of the 1617 participants, $815(50.4 \%)$ reported fully met care needs and $802(49.6 \%)$ reported unmet care needs. Among the sociodemographic characteristics, there was a statistically significant difference in terms of education $\left(\chi^{2}=7.716, p=0.021\right)$ and place of residence $\left(\chi^{2}=23.487, p<0.001\right)$. Mean frailty index was higher for the undermet care needs group $(t=-9.165, p<0.001)$. There were no significant differences between groups in terms of sex, age or marital status. 
Table 2. Sociodemographic characteristics according to undermet care needs.

\begin{tabular}{|c|c|c|c|c|c|}
\hline \multirow{2}{*}{\multicolumn{2}{|c|}{ Variables }} & $\begin{array}{l}\text { Undermet Care Needs } \\
(\mathrm{n}=802)\end{array}$ & $\begin{array}{l}\text { Fully Met Care Needs } \\
\qquad(\mathrm{n}=815)\end{array}$ & \multirow[t]{2}{*}{ t or $\chi^{2}$} & \multirow[t]{2}{*}{$p$-Value } \\
\hline & & \multicolumn{2}{|c|}{ n (\%)/Mean (S.D.) } & & \\
\hline \multirow{2}{*}{ Sex } & female & $618(50.24)$ & $612(49.76)$ & \multirow{2}{*}{0.858} & \multirow{2}{*}{0.354} \\
\hline & male & $184(47.55)$ & $203(52.45)$ & & \\
\hline \multirow{3}{*}{ Age } & 80 to 90 & $73(56.59)$ & $56(43.41)$ & \multirow{3}{*}{4.810} & \multirow{3}{*}{0.090} \\
\hline & 91 to 100 & $384(47.29)$ & $428(52.71)$ & & \\
\hline & $>100$ & $345(51.04)$ & $331(48.96)$ & & \\
\hline \multirow{3}{*}{ Education (years) } & No formal education & $574(71.57)$ & $542(66.50)$ & \multirow{3}{*}{7.716} & \multirow{3}{*}{0.021} \\
\hline & 1 to 6 & $196(24.44)$ & $219(26.87)$ & & \\
\hline & 7 or more & $32(3.99)$ & $54(6.63)$ & & \\
\hline \multirow{2}{*}{ Marital status } & have no spouse & 759 (49.58) & $772(50.42)$ & \multirow{2}{*}{0.071} & \multirow{2}{*}{0.790} \\
\hline & have spouse & $36(48.00)$ & $39(52.00)$ & & \\
\hline \multirow{3}{*}{ Place of residence } & urban & 147 (39.30) & $227(60.70)$ & \multirow{3}{*}{23.487} & \multirow{3}{*}{$<0.001$} \\
\hline & town & $264(49.91)$ & $265(50.09)$ & & \\
\hline & rural & $391(54.76)$ & $323(45.24)$ & & \\
\hline \multicolumn{2}{|c|}{ frailty index } & 0.43 & 0.38 & -9.165 & $<0.001$ \\
\hline
\end{tabular}

We employed binary logistic regression analysis to investigate the association between undermet care needs of disabled oldest old people and the four categories of influencing factors. The results are shown in Table 3. Of the sociodemographic characteristics, living in a rural area $(\mathrm{OR}=1.309,95 \% \mathrm{CI}=1.133-1.513)$ and a higher frailty index $(\mathrm{OR}=1.103,95 \% \mathrm{CI}=1.075-1.131)$ were significantly positively associated with higher odds for undermet care needs of the disabled oldest old people. However, sex, age, education level and marital status were not significantly associated. In terms of family endowment, a higher annual household income $(\mathrm{OR}=0.856,95 \% \mathrm{CI}=0.795-0.923)$ was significantly inversely associated with higher odds for undermet care needs, while the number of cohabitating family members was not significantly associated. In terms of intergenerational relationships, more children's financial support $(\mathrm{OR}=0.969,95 \% \mathrm{CI}=0.941-0.997)$, higher care expenditure $(\mathrm{OR}=1.044,95 \% \mathrm{CI}=1.002-1.088)$ and better caregiver's performance $(\mathrm{OR}=0.282$, $95 \% \mathrm{CI}=0.196-0.407)$ were significantly inversely associated with higher odds for undermet care needs of the disabled oldest old people. However, the frequency of sharing feelings with their caregiver was not significantly associated. In terms of economic bargaining power, income sufficient for paying daily expenses $(\mathrm{OR}=0.710,95 \% \mathrm{CI}=0.519-0.973)$ was significantly inversely associated with higher odds for undermet care needs of the disabled oldest old people, while having real estate in one's own name and having public old age insurance were not significantly associated.

Table 3. Binary logistic regression analysis of the influencing factors for undermet care needs in the disabled oldest old people.

\begin{tabular}{|c|c|c|c|c|c|}
\hline Variables & Odds Ratio & SE & z-Values & $p$-Values & $95 \% \mathrm{CI}$ \\
\hline Sex & 1.195 & 0.166 & 1.28 & 0.201 & $0.910-1.568$ \\
\hline Age & 0.988 & 0.011 & -1.12 & 0.261 & $0.967-1.009$ \\
\hline Education & 0.911 & 0.096 & -0.89 & 0.376 & $0.742-1.119$ \\
\hline Marital status & 0.767 & 0.203 & -1.00 & 0.316 & $0.457-1.288$ \\
\hline Place of residence & 1.308 & 0.096 & 3.65 & 0.000 & $1.132-1.510$ \\
\hline Frailty index & 1.102 & 0.014 & 7.43 & 0.000 & $1.074-1.130$ \\
\hline Number of cohabitating family members & 1.011 & 0.033 & 0.32 & 0.751 & $0.947-1.078$ \\
\hline Annual household income & 0.856 & 0.033 & -4.07 & 0.000 & $0.795-0.923$ \\
\hline Children's financial support & 0.969 & 0.014 & -2.09 & 0.037 & $0.942-0.998$ \\
\hline Care expenditure & 1.043 & 0.022 & -1.99 & 0.046 & $1.001-1.087$ \\
\hline Caregiver's performance & 0.249 & 0.049 & -7.08 & 0.000 & $0.169-0.365$ \\
\hline Share feelings with the caregiver & 0.903 & 0.085 & -1.08 & 0.280 & $0.750-1.087$ \\
\hline Income sufficient for paying daily expenses & 0.719 & 0.116 & -2.05 & 0.041 & $0.524-0.986$ \\
\hline Have real estate in own name & 1.038 & 0.147 & 0.26 & 0.793 & $0.786-1.371$ \\
\hline Public old age pension & 1.086 & 0.133 & 0.68 & 0.499 & $0.855-1.380$ \\
\hline
\end{tabular}

Note: SE represent standard error. 


\section{Discussion}

\subsection{Main Findings and Opinions}

With the rapid increase of China's aging population, the care model for older children taking care of their oldest old parents is increasingly prevalent. To the best of our knowledge, our study is the first to explore the care model of older children taking care of their oldest old parents. In addition, as opposed to previous studies focused on factors related to undermet care needs [47-49], which were mainly based on the theory of Andersen's behavioral model of health services use; our analysis of the undermet care needs was based on the background of Chinese traditional filial piety culture and the strong inertial family care model, which could fill a research gap in this field. Further, our study used nationwide data from 2018 of Chinese disabled oldest old people, which could better reflect the latest situation of undermet care needs among the oldest old population in China.

The results of our study showed that, in terms of sociodemographic characteristics, living in rural areas was associated with having more undermet care needs, which was also found in previous studies [46]. In China, due to the substantial disparities in terms of economic development level, medical, and care resources between rural and urban areas, older children as caregivers in rural families provided fewer care resources than those in urban families; therefore, rural disabled oldest old people reported more undermet care needs. Our study also found that poor health status as indicated by a higher frailty index was associated with having more undermet care needs, which was supported by previous studies $[47,64]$. We used the frailty index to comprehensively measure the health conditions of the disabled oldest old people, which could better explore related health factors. Further, our study found that gender, age, education level and marital status were not significantly associated with undermet care needs of the disabled oldest old people. Previous studies on sociodemographic factors, including gender, age, education level and marital status, produced mixed results $[24,41,53,54]$.

In terms of family endowment, we found that a lower annual household income was associated with having more undermet care needs among the disabled oldest old people, which agreed with previous studies [71,72]. However, in contrast with findings of previous studies [47,59], we found that the number of cohabitating family members was not associated with undermet care needs. One explanation for this discrepancy was that caring for the disabled oldest old people is both a time-intensive and labor-intensive activity requiring substantial amounts of time and patience, and it is possible that multiple cohabitants may shirk the responsibility of providing care, thereby not necessarily contributing to lowering undermet care needs. Another explanation is that since multiple generations live together, the care needs of the older people may not be able to be satisfied when family resources are limited and the older people have less power in the distribution of family resources.

In terms of intergenerational relationships, more children's financial support, more care expenditure and better caregiver's performance were inversely associated with having more undermet care needs, which was supported by the findings of previous studies $[46,47,59,66]$. To a certain extent, the care expenditure reflects the explicit cost in the process of family care for Chinese disabled oldest old people. The more care expenditure, the more resources put into care process, and the lower the undermet care needs of the disabled oldest old people. As for the care performance, it includes both the caregiver's objective care behavior and the caregiver's subjective attitude. Therefore, it is a more comprehensive concept. Better care performance means that the caregiver's behaviors are more in line with the care needs of the older people, and there are more love and positive emotions involved in the care process. However, the frequency of sharing feelings with the caregiver was not associated with undermet care needs. The explanation for this finding may be that regular emotional communication with older children does not necessarily/always bring about improvements in care among disabled oldest old people. Financial transfers matter the most. On the one hand, more children's financial support and care expenditure means more care resources are put into the care by older children, and therefore, there are fewer undermet care needs. On the other hand, older children may be more concerned about whether they can obtain financial compensation or rewards from their oldest 
old parents, which will motivate their enthusiasm for providing care and improve the quality of care $[21,63,66]$.

In terms of the economic bargaining power of the oldest old people, their income being insufficient to pay for their daily expenses was associated with having more undermet care needs, consistent with the findings of previous studies $[46,54]$. However, having real estate in one's own name and having public old age insurance were not associated. There are possible explanations for these two factors. First, the Chinese oldest old people had less real estate. In the present study, we found that more than $80 \%$ of the oldest old disabled people did not own real estate. Second, influenced by the traditional concept of inheritance, real estate will be naturally bequeathed to their children. Thus, it is difficult for the oldest old people to mobilize their children's enthusiasm for providing care through house property rights. That is also the reason why a house for pension program (Housing Reverse Mortgagin) could not be promoted in China [73,74]. In addition, the public old age pension of the oldest old people is low; whether there was a pension had little effect on the economic bargaining power of the oldest old people; therefore, it could not mobilize their children's enthusiasm for care and was not associated with undermet care needs.

\subsection{Limitations and Future Works}

The present study has several limitations. First, the undermet care needs of the disabled oldest old people were evaluated with only one subjective item; it is possible that self-rated undermet care needs can be used to measure the relationship between the caregiver and care recipient, rather than true willingness. Second, due to the constraints of the data, this study lacked data on care-resource factors, such as care intensity, and primary caregiver-related information, such as education, health status, employment and income. At the same time, caring is a two-way interactive process, and the attitude and assessment of caregivers regarding care needs is also important, which was not included in our study. Future studies of the care model of older children caring for their oldest old parents should focus more attention on older children caregivers. Third, our study only used one cross-sectional dataset, which could not reflect changes in undermet care needs. Although we tried to use longitudinal data, there were too few samples after matching two or three waves of CLHLS data. Additionally, there were few nationwide census data on the oldest old people in China. Future studies should further expand the sample size or develop a nationwide census for the Chinese oldest old people to make the sample information more abundant.

\section{Conclusions}

Given that family care still has a strong institutional inertia and cultural identity, the care model of older children taking care of their oldest old parents is still reasonable but faces some challenges. Due to the aging population structure, the increasing geographical mobility of the population, the increase in the employment rate of women, and the weakening of traditional values [31,32,39], the availability of potential family caregivers is declining. First, declines in both mortality and fertility have not only accelerated population aging but have also decreased the size of families. Second, increased geographical mobility means fewer family members live near to care for older people. The impact of these changes has been shifting family structures from the traditional extended family to the nuclear family, decreasing the level of available intergenerational support. Third, as females are the main family caregivers, an increasing number of women entering the labor force means they are less available to be primary caregivers in their family. Finally, modernization and individualization have eroded the core traditional value-filial piety. All these challenges have contributed to the decline in the number of available caregivers and have made the informal older-care system even more vulnerable.

Therefore, there are some policy implications of care for disabled oldest old people. First, it is crucial to establish a comprehensive, sustainable, available and affordable long-term care system to increase formal services, such as paid home service and community-based care services. Second, given that the Chinese long-term care insurance is still in the pilot stage, it is important to promote long-term 
care insurance as soon as possible and to offer nursing assistance to those in need. In addition, because economic status is associated with undermet care needs, it is of great significance to provide financial assistance to the oldest old people to enhance their economic accessibility to care services, particularly those residents in rural areas where undermet needs are more prevalent and female oldest old people who live especially long lives. In particular, the payment standard of old age pension and allowance should be improved to provide more financial support. Third, the role of family caregivers and relevant support policies for them should be highly valued. The family caregiver support policy should be embedded in a series of policies in terms of population, family, fiscal and taxation. Additionally, it is necessary to focus on programs that provide care skills training, respite services, and psychological counseling for family caregivers and to try to pilot a family caregiver allowance.

Author Contributions: E.L. and Q.Z. described the proposed framework and wrote the whole manuscript; Y.W. and E.L. wrote the original draft; E.L. and Y.W. collected data; E.L. and Q.Z. revised the manuscript. All authors have read and agreed to the published version of the manuscript.

Funding: This research is supported by the Programme of Introducing Talents of Discipline to Universities of the Ministry of Education and the Ministry of Science and Technology of China (B20084), National Social Science Foundation of China (Grant No. 20VYJ030), Major Project of Humanities and Social Sciences of Ministry of Education of China (Grant No. 15JJD630009) (Grant No. 16JJD840009), National Natural Science Foundation of China (Grant No. 71973154) (Grant No. 72074224), Foundation of Humanities and Social Sciences of Ministry of Education of China (Grant No. 19YJA840006).

Acknowledgments: Data used in this research were provided by the project entitled "Chinese Longitudinal Longevity Survey" (CLHLS) that was jointly implemented by the Center for Healthy Aging and Development Studies of Peking University and Duke University. CLHLS is supported by funds from the U.S. National Institutes on Aging (NIA), China Natural Science Foundation, China Social Science Foundation, and UNFPA.

Conflicts of Interest: The authors declare that they have no competing interests.

\section{References}

1. Statistical Bulletin of the People's Republic of China on National Economic and Social Development in 2019. Available online: http://www.stats.gov.cn/tjsj/zxfb/202002/t202002281728913.html (accessed on 15 May 2020). (In Chinese)

2. United Nations Department of Economic and Social Affairs. World Population Prospects: The 2019 Revision. Available online: https://population.un.org/wpp/Download/Standard/Population/ (accessed on 15 May 2020). (In Chinese)

3. Mu, G.Z. The Graying of China: From the Universal Two-Child Policy to Successful Aging; China Democratic and Legal Publishing House: Beijing, China, 2016; pp. 28-46. (In Chinese)

4. United Nations Department of Economic and Social Affairs. World Population Prospects: The 2012 Revision. Available online: https://population.un.org/wpp/Download/Archive/Standard/ (accessed on 15 May 2020). (In Chinese)

5. World Health Organization. China Country Assessment Report on Ageing and Health. Available online: https://www.who.int/ageing/publications/china-country-assessment/en/ (accessed on 16 May 2020).

6. Zeng, Y.; Feng, Q.S.; Therese, H.; Kaare, C.; James, W.V. Survival, disabilities in activities of daily living, and physical and cognitive functioning among the oldest-old in china: A cohort study. Lancet 2017, 389, 1619-1629. [CrossRef]

7. Feng, Y.; Liu, E.P.; Yue, Z.; Zhang, Q.L.; Han, T.K. The evolutionary trends of health behaviors in Chinese elderly and the influencing factors of these trends: 2005-2014. Int. J. Environ. Res. Public Health 2019, 16, 1687. [CrossRef] [PubMed]

8. China National Committee on Aging. The Fourth Sampling Survey Result on the Living Conditions of Urban and Rural Elderly People in China. Available online: http://jnjd.mca.gov.cn/article/zyjd/xxck/201610/ 20161000886652.shtml (accessed on 16 May 2020). (In Chinese)

9. Drafting Group of the General Report of the National Aging Office. The general research report of Chinese strategic for dealing with population aging. Sci. Res. Aging 2015, 3, 4-38. (In Chinese)

10. Zeng, Y.; Poston, D.L.; Vlosky, D.A.; Gu, D.N. Healthy Longevity in China: Demographic, Socioeconomic, and Psychological Dimensions; Springer Science \& Business Media: New York, NY, USA, 2008; pp. $23-39$. 
11. Liang, Y.; Song, A.; Du, S.; Guralnik, J.M.; Qiu, C. Trends in disability in activities of daily living among Chinese older adults, 1997-2006: The China health and nutrition survey. J. Gerontol. A-Biol. 2015, 6, 739-745. [CrossRef]

12. Zhang, Q.L.; Wu, Y.L.; Han, T.K.; Liu, E.P. Changes in cognitive function and risk factors for cognitive impairment of the elderly in China: 2005-2014. Int. J. Environ. Res. Public Health 2019, 16, 2847. [CrossRef]

13. Martin, L.G.; Feng, Q.; Schoeni, R.F.; Zeng, Y. Trends in functional and activity limitations among Chinese oldest-old, 1998 to 2008. Popul. Dev. Rev. 2014, 3, 475-495. [CrossRef]

14. Jiang, X.Q.; Wei, M.; Zhang, W.J. Study on the health status and influencing factors of China's aging population. Popul. J. 2015, 2, 46-56. (In Chinese)

15. Chen, F.N.; Korinek, K. Family life course transitions and rural household economy during China's market reform. Demography 2007, 47, 963-987. [CrossRef]

16. Zuo, D.M.; Wu, Z.; Li, S.Z. Age, and inter-generational exchange among older parents in rural China. Int. J. Soc. Welf. 2011, 20, S30-S46. [CrossRef]

17. Fan, Y.; Fang, S.; Yang, Z. Living arrangements of the elderly: A new perspective from choice constraints in China. China Econ. Rev. 2018, 50, 101-116. [CrossRef]

18. Du, P. An analysis on the health status of the older persons in China. Popul. Econ. 2013, 6, 3-9. (In Chinese)

19. Zeng, Y.; Liu, Y.Z.; Xiao, Z.Y.; Zhang, C.Y. The socio-demographic and health status of the oldest-old in China. Chin. J. Popul Sci. 2013, 1, S6-S15. (In Chinese)

20. Korinek, K.; Zimmer, Z.; Gu, D. Transitions in marital status and functional health and patterns of intergenerational coresidence among China's elderly population. J. Gerontol. B-Psychol. 2011, 2, 260-270. [CrossRef] [PubMed]

21. Jiang, Q.B.; Li, X.M.; Jesús, J.S.B. Elderly widowhood in China. Asian Popul. Stud. 2015, 11, 7-16. [CrossRef]

22. Cantor, M.H. The Informal Support System: Its Relevance in the Lives of the Elderly; Sage Publications: Beverly Hills, CA, USA, 1980; pp. 131-144.

23. Giles, J.; Wang, D.; Zhao, C. Can China's rural elderly count on support from adult children? Implications of rural-to-urban migration. J. Popul. Ageing 2010, 3, 183-204. [CrossRef]

24. Ding, Z.H. Distribution of care resources and care satisfaction of the oldest old in China. Popul. Res. 2011, 5, 102-110. (In Chinese)

25. Gu, L.; Rosenberg, M.W.; Zeng, J.X. Changing caregiving relationships for older home-based Chinese people in a transitional stage: Trends, factors and policy implications. Arch. Gerontol. Geriatr. 2017, 70, 219-229. [CrossRef]

26. Shen, S.Y.; Li, F.; Tanui, J.K. Quality of life and old age social welfare system for the rural elderly in China. Ageing Int. 2012, 37, 285-299. [CrossRef]

27. Dorfman, M.C.; Holzmann, R.; O’Keefe, P.; Wang, D.; Sin, Y.; Hinz, R. China's Pension System: A Vision; World Bank: Washington, DC, USA, 2013; pp. 15-69.

28. Queisser, M.; Reilly, A.; Hu, Y. China's pension system and reform: An OECD perspective. Econ. Political Stud. 2016, 4, 345-367. [CrossRef]

29. Du, P.; Sun, J.J.; Zhang, W.J.; Wang, X.F. The demands of old-age care and the family and social resources for the Chinese elderly: A study base on 2014 China longitudinal aging social survey. Popul. Res. 2016, 6, 49-61. (In Chinese)

30. Shen, Y.F.; Chen, H. Policy review and empirical study on China's old-age-allowance system. Popul. Econ. 2016, 1, 50-56. (In Chinese)

31. Feng, Z.; Liu, C.; Guan, X.; Mor, V. China's rapidly aging population creates policy challenges in shaping a viable long-term care system. Health Aff. 2012, 31, 2764-2773. [CrossRef] [PubMed]

32. Wu, B.; Carter, M.W.; Goins, R.T.; Cheng, C. Emerging services for community-based long-term care in urban China: A systematic analysis of Shanghai's community-based agencies. J. Aging Soc. Policy 2005, 17, 37-60. [CrossRef] [PubMed]

33. Fei, X.T. Supporting for the elderly in the change of family structure. J. Peking Univ. (Humanit. Soc. Sci.) 1983, 3, 6-15. (In Chinese)

34. Cheng, S.T.; Chan, A.C.M. Filial piety and psychological well-Being in well older Chinese. J. Gerontol. B-Psychol. 2006, 61, 262-269. [CrossRef]

35. Huang, V.; Fiocco, A.J. Measuring perceived receipt of filial piety among Chinese middle-aged and older adults. J. Cross Cult. Gerontol. 2020, 35, 195-208. [CrossRef] 
36. Lai, D. Depressive symptoms of elderly Chinese in Guangzhou, Hong Kong, and Taipei. Aging Ment. Health 2009, 13, 25-35. [CrossRef]

37. Liu, T.; Sun, L. An apocalyptic vision of ageing in China: Old age care for the largest elderly population in the world. Z. Gerontol. Geriatr. 2015, 48, 354-364. [CrossRef]

38. Sun, J.J.; Mei, C.Y.C.; Chen, H.J. Gerontology and Aging: An International Perspective; China Renmin University Press: Beijing, China, 2014; pp. 94-124.

39. Gu, D.; Vlosky, D.A. Long-term care needs and related issues in China. In Social Sciences in Health Care and Medicine; Garner, J.B., Christiansen, T.C., Eds.; Nova Science Publishers: New York, NY, USA, 2008; pp. 52-84.

40. Kennedy, J. Unmet and undermet need for activities of daily living and instrumental activities of daily living assistance among adults with disabilities: Estimates from the 1994 and 1995 disability follow-back surveys. Med. Care 2001, 39, 1305-1312. [CrossRef]

41. Allen, S.M.; Mor, V. The prevalence and consequences of unmet need: Contrasts between older and younger. Med. Care 1997, 35, 1132-1148. [CrossRef]

42. Komisar, H.L.; Feder, J.; Kasper, J.D. Unmet long-term care needs: An analysis of medicare-medicaid dual eligibles. Inquiry 2005, 42, 171-182. [CrossRef]

43. DePalma, G.; Xu, H.; Covinsky, K.E.; Craig, B.A.; Stallard, E.; Thomas, J.; Sands, L.P. Hospital readmission among older adults who return home with unmet need for ADL disability. Gerontologist 2012, 53, 454-461. [CrossRef]

44. Quail, J.M.; Wolfson, C.; Lippman, A. Unmet need for assistance to perform activities of daily living and psychological distress in community-dwelling elderly women. Can. J. Aging 2011, 30, 591-602. [CrossRef]

45. Zhen, Z.; Feng, Q.; Gu, D. The impacts of unmet needs for long-term care on mortality among older adults in China. J. Disabil. Policy Stud. 2015, 25, 243-251. [CrossRef]

46. Peng, R.; Wu, B.; Ling, L. Undermet needs for assistance in personal activities of daily living among community-dwelling oldest old in China from 2005 to 2008. Res. Aging 2015, 37, 148-170. [CrossRef]

47. Zhu, H.Y. Unmet needs in long-term care and their associated factors among the oldest old in China. BMC Geriatr. 2015, 15, 46. [CrossRef]

48. Fortin, M.; Bamvita, J.M.; Fleury, M.J. Patient satisfaction with mental health services based on Andersen's Behavioral Model. Can. J. Psychiatry 2018, 63, 103-114. [CrossRef]

49. Desai, M.M.; Lentzner, H.R.; Weeks, J.D. Unmet need for personal assistance with activities of daily living among older adults. Gerontologist 2001, 41, 82-88. [CrossRef]

50. Zeng, Y.; Vaupel, J.W.; Xiao, Z.; Zhang, C.; Liu, Y. The healthy longevity survey and the active life expectancy of the oldest old in China. Popul. Engl. Sel. 2001, 13, 95-116.

51. Katz, S.; Ford, A.B.; Moskowitz, R.W.; Jackson, B.A.; Jaffe, M.W. Studies of illness in the aged the index of ADL: A standardized measure of biological and psychosocial function. JAMA 1963, 185, 914-919. [CrossRef]

52. Williams, J.; Lyons, B.; Rowland, D. Unmet long-term care needs of elderly people in the community: A review of the literature. Home Health Care Serv. Q. 1997, 16, 93-119. [CrossRef]

53. Momtaz, Y.A.; Hamid, T.A.; Ibrahim, R. Unmet needs among disabled elderly Malaysians. Soc. Sci. Med. 2012, 75, 859-863. [CrossRef]

54. Hang, K.S. Study on satisfaction and its factors of daily care needs of Chinese oldest-old. Popul. Resour. Environ. 2014, 3, S331-S334. (In Chinese)

55. Zhu, Y.M.; Österle, A. Rural-urban disparities in unmet long-term care needs in China: The role of the hukou status. Soc. Sci. Med. 2017, 191, 30-37. [CrossRef]

56. Romero-Ortuno, R.; Kenny, R.A. The frailty index in Europeans: Association with age and mortality. Age Ageing 2012, 41, 684-689. [CrossRef]

57. Searle, S.D.; Mitnitski, A.; Gahbauer, E.A.; Gill, T.M.; Rockwood, K. A standard procedure for creating a frailty index. BMC Geriatr. 2008, 8, 24. [CrossRef]

58. Ye, B.; Chen, H.; Huang, L.; Ruan, Y.; Qi, S.; Guo, Y.; Huang, Z.; Sun, S.; Chen, X.; Shi, Y.; et al. Changes in frailty among community-dwelling Chinese older adults and its predictors: Evidence from a two-year longitudinal study. BMC Geriatr. 2020, 20, 130. [CrossRef]

59. Liu, Y.H.; Chang, H.J.; Huang, C.C. The unmet activities of daily living (ADL) needs of dependent elders and their related factors: An approach from both an individual and area-level perspective. Int. J. Gerontol. 2012, 6, 163-168. [CrossRef] 
60. Casado, B.L.; van Vulpen, K.S.; Davis, S.L. Unmet needs for home and community-based services among frail older Americans and their caregivers. J. Aging Health 2011, 23, 529-553. [CrossRef]

61. Hoebe, J.; Rommel, A.; Schröder, S.L.; Fuchs, J.; Nowossadeck, E.; Lampert, T. Socioeconomic inequalities in health and perceived unmet needs for healthcare among the elderly in Germany. Int. J. Environ. Res. Public Health 2017, 14, 1127. [CrossRef]

62. Boaz, R.F.; Hu, J.; Ye, Y. The transfer of resources from middle-aged children to functionally limited elderly parents: Providing time, giving money, sharing space. Gerontologist 1999, 39, 648-657. [CrossRef] [PubMed]

63. Deindl, C.; Brandt, M. Financial support and practical help between older parents and their middle-aged children in Europe. Ageing Soc. 2011, 31, 645-662. [CrossRef]

64. Chen, J.; Jordan, L.P. Intergenerational support and life satisfaction of young-, old- and oldest-old adults in China. Aging Ment. Health 2018, 22, 412-420. [CrossRef] [PubMed]

65. Kocot, E. The impact of aging on different types of health care: The example of the Polish health insurance system. Int. J. Health Plan. Manag. 2018, 33, e557-e568. [CrossRef]

66. Liu, E.P.; Zhang, Q.L. Analysis of the changing trend and care-giving effect of children caring for disabled elderly. Econ. Perspect. 2018, 6, 92-105. (In Chinese)

67. Liu, B.S.; Huang, H.C. Family care for the elderly and the importance of filial piety. Hu Li Za Zhi 2009, 56, $83-88$.

68. Fu, Y.Y.; Guo, Y.; Bai, X.; Chui, E.W. Factors associated with older people's long-term care needs: A case study adopting the expanded version of the Anderson Model in China. BMC Geriatr. 2017, 17, 38. [CrossRef]

69. National Alliance for Caregiving; AARP. Just Getting by: Unmet Need for Personal Assistance Services among Persons 50 or Older with Disabilities; National Alliance for Caregiving: Washington, DC, USA, 2009.

70. Reeves, A.; McKee, M.; Mackenbach, J.; Whitehead, M.; Stuckler, D. Public pensions and unmet medical need among older people: Cross-national analysis of 16 European countries, 2004-2010. J. Epidemiol. Community Health 2017, 71, 174-180. [CrossRef]

71. Zeng, L.; Xu, X.C.; Zhang, C.X.; Chen, L.H. Factors influencing long-term care service needs among the elderly based on the latest Anderson Model: A case study from the middle and upper reaches of the Yangtze river. Healthcare 2019, 7, 157. [CrossRef]

72. Yeung, W.J.J.; Thang, L.L. Long-term care for older adults in ASEAN plus three: The roles of family, community, and the state in addressing unmet eldercare needs. J. Aging Health 2018, 30, 1499-1515. [CrossRef]

73. Wang, Y.K.; Ye, Y.T.; Tang, S. House-for-pension: Experiences, dilema and prospects in China. Jianghai Acad. J. 2020, 1, 240-245.

74. Zhang, D. House-for-pension scheme in China: Realistic dilemma, international experience and strategies. Contemp. Econ. Manag. 2020, 2, 70-77. 